\title{
Saúde como direito humano: vivências do cotidiano no SUS
}

\author{
Health as human right: everyday experiences in the SUS \\ La salud como derecho humano: vivencias cotidianas en el SUS
}

Recebido: 19/09/2021 | Revisado: 25/09/2021 | Aceito: 27/09/2021 | Publicado: 27/09/2021

\author{
Michele Franciele Rodrigues dos Santos \\ ORCID: https://orcid.org/0000-0002-4441-4630 \\ Universidade do Vale do Rio dos Sinos, Brasil \\ E-mail: michelefranciele@yahoo.com.br \\ Marla Fernanda Kuhn \\ ORCID: https://orcid.org/0000-0001-9228-6226 \\ Universidade Federal do Rio Grande do Sul, Brasil \\ E-mail: marlakuhn2016@gmail.com
}

\begin{abstract}
Resumo
Este estudo tem por objetivo descrever como ocorre o acesso ao direito à saúde dos usuários da Atenção Primária à Saúde do Sistema Único de Saúde, em uma unidade básica de saúde da região metropolitana de Porto Alegre, RS. Trata-se de artigo sistematizado por meio de relato da experiência de residente do curso de Residência Multiprofissional em Atenção Básica em seu campo de prática na Atenção Primária à Saúde. Este serviço se caracteriza como uma unidade mista, ou seja, além de Unidade Básica de Saúde possui uma Estratégia de Saúde da Família. O trabalho foi realizado junto aos usuários do sistema de saúde, sendo que este processo de vivência ocorreu entre o segundo semestre de 2018 e o ano de 2019, período no qual participamos da Residência. Durante este período, procurou-se estabelecer uma escuta qualificada dos usuários, possibilitando que durante as abordagens fosse realizada uma ambiência interativa para a construção dos diálogos entre as profissionais e os usuários. Os instrumentos e procedimentos utilizados neste estudo foram: observação participante, escuta qualificada e diário de campo, utilizado para a sistematização e registro do vivido. Estes registros ocorreram durante as abordagens individuais ou coletivas, interconsultas com outros profissionais do serviço, acolhimento, sala de espera e atividades coletivas. O estudo apontou que ainda estamos longe de ver garantidos os direitos dos usuários do SUS, sistema cada vez mais sucateado em prol dos interesses dos sistemas privados de saúde. Nossa intenção é contribuir para a reflexão sobre a temática direitos dos usuários e sobre a importância da participação popular para poder garanti-lo. Esta experiência pode ser um estímulo para a construção de possibilidades de ampliação da cidadania.
\end{abstract}

Palavras-chave: Direto humano à saúde; Acesso universal a serviços saúde; Atenção Primária à Saúde.

\begin{abstract}
This study aims to describe the access to the right to health of users of the Primary Health Care of the Unified Health System, in a basic health unit in the metropolitan region of Porto Alegre, RS. This article is systematized by reporting the experience of a resident of the Multiprofessional Residency course in Primary Care in its field of practice in Primary Health Care. This service is characterized as a mixed unit, that is, in addition to the Basic Unit of Saúde has a Family Health Strategy. The work was carried out with users of the health system, and this experience process took place between the second half of 2018 and the year 2019, period in which we participated in the Residency. During this period, we tried to establish a qualified listening to the users, enabling an interactive environment to be held during the approaches for the construction of dialogues between the professionals and the users. The instruments and procedures used in this study were: participant observation, qualified listening and a field diary, used to systematize and record what was experienced. These records occurred during individual or collective approaches, consultations with other service professionals, reception, waiting room and collective activities. The study pointed out that we are still far from being guaranteed the rights of SUS users, a system that is increasingly scrapped in favor of the interests of private health systems. Our intention is to contribute to the reflection on the theme of users' rights and on the importance of popular participation in order to guarantee it. This experience can be a stimulus for the construction of possibilities for expanding citizenship.
\end{abstract}

Keywords: Human right to health; Universal access to health services; Primary Health Care.

\section{Resumen}

Este estudio tiene como objetivo describir cómo se da el acceso al derecho a la salud de los usuarios de la Atención Primaria de Salud del Sistema Único de Salud, en una unidad básica de salud de la Región Metropolitana de Porto Alegre, RS. Este artículo se sistematiza reportando la experiencia de un residente del curso de Residencia Multiprofesional en Atención Primaria en su campo de práctica en Atención Primaria de Salud. Este servicio se caracteriza por ser una unidad mixta, es decir, además de la Unidad Básica de Salud Saúde tiene una estrategia de 
salud familiar. El trabajo se realizó con usuarios del sistema de salud, y este proceso de experiencia se desarrolló entre el segundo semestre de 2018 y el año 2019, período en el que participamos en la Residencia. Durante este período, intentamos establecer una escucha calificada de los usuarios, posibilitando que se desarrolle un ambiente interactivo durante los acercamientos para la construcción de diálogos entre los profesionales y los usuarios. Los instrumentos y procedimientos utilizados en este estudio fueron: observación participante, escucha calificada y un diario de campo, utilizado para sistematizar y registrar lo vivido. Estos registros ocurrieron durante acercamientos individuales o colectivos, consultas con otros profesionales del servicio, recepción, sala de espera y actividades colectivas. El estudio señaló que aún estamos lejos de tener garantizados los derechos de los usuarios del SUS, un sistema cada vez más desechado a favor de los intereses de los sistemas privados de salud. Nuestra intención es contribuir a la reflexión sobre el tema de los derechos de los usuarios y sobre la importancia de la participación popular para garantizarlo. Esta experiencia puede ser un estímulo para la construcción de posibilidades de expansión ciudadana.

Palabras clave: Derecho humano a la salud; Acceso universal a los servicios de salud; Atención Primaria de la salud.

\section{Introdução}

A Saúde é um direito de todos e de todas e um dever do estado, anunciado na Carta Constitucional Brasileira. Esta concepção de saúde, compreendida como direito humano, foi deliberada na $8^{\text {a }}$ Conferência Nacional de Saúde, em 1986, e conquistou legitimidade na Constituição Federal de 1988 (Paim, 2013) (Centro de Educação e Assessoramento Popular, 2017).

A Constituição da República Federativa do Brasil, é a lei fundamental e suprema do nosso País, foi promulgada em cinco de outubro de 1988, por uma Assembleia Constituinte formada por deputados e senadores eleitos. A aprovação desta Carta Magna é considerada a plenitude da redemocratização brasileira e o marco do início da democracia após anos de ditadura militar. Nela a saúde foi instituída e reconhecida como um direito social e de garantia fundamental (Paim, 2013).

No entanto, a declaração constituinte da "saúde como direito de todos e dever do estado", não impede que no modo de se produzir saúde ocorra conflito entre dois conceitos antagônicos: um que tem a saúde como objeto de lucro, direcionado na abordagem individual; e outro que sustenta a saúde como direito humano, com uma abordagem individual-coletiva (Centro de Educação e Assessoramento Popular, 2017).

Sob este prisma da relação saúde e direito, examinam-se as tensões que operam no campo da saúde, um campo de luta e tensão social, no qual se enfrenta as várias apostas sociais sobre a produção do sentido das vidas individuais e coletivas. Deste modo, este processo de produzir ou lutar contra as desigualdades sociais coloca em evidencia que tipos de produção de vidas humanas lutamos para conquistar. Concordamos com a perspectiva de que "qualquer vida vale a pena" (Merhy, 2012).

Este estudo foi desenvolvido numa perspectiva de saúde ampliada. Refere-se à lógica da determinação social dos processos de saúde e doença para a consolidação da saúde como direito humano.

No artigo 196, da Constituição Federal de 1988, a saúde é declarada como direito de todo (a) cidadão (ã) brasileiro (a) e de responsabilidade do Estado, e deve estar garantida por meio de políticas sociais e econômicas que visem à redução do risco de doença e de outros agravos e o acesso universal e igualitário às ações e serviços para sua promoção, proteção e recuperação da saúde (Brasil, 1998).

Em 2018, ao completar 30 anos da Constituição Federal, ainda é possível observar que muitos desses direitos apresentam lacunas na garantia do acesso dos usuários, sendo negligenciados e até mesmo violados. No que diz respeito ao direito à saúde, seja pelo SUS ou através da saúde suplementar, o que se observa são muitas barreiras para acessar os diferentes serviços que compõem a Rede de Atenção à Saúde (RAS) (Molina, 2018). No ano de 2018, também comemoramos os 40 anos da Declaração de Alma-Ata e os 30 anos do SUS. Conduzidos nas memórias, relembramos os trajetos que nos trouxeram até o contexto que vivemos.

Em 1975, a Organização Mundial da Saúde (OMS), após a realização de uma assembleia deliberativa, designa a implementação de sistemas nacionais de Atenção Primária à Saúde (APS), e esta deveria ser considerada pelos gestores dos Estados uma prioridade absoluta. Um ano depois, em 1976, firma a meta "Saúde para Todos no ano 2000" (Mendonça, 
2018). Após, em 1978, foi publicada a Declaração de Alma-Ata, documento essencial para o desenvolvimento da APS, e guia fundamental para a criação e aprimoramento dos sistemas de saúde mundialmente (Molina, 2018).

Neste momento, no Brasil, eram vividos fatos históricos de redemocratização, que demarcou o fim do governo militar e a promulgação da Carta Constitucional brasileira, em 1988. Em decorrência disto, foi criado um sistema unificado de saúde, público, universal e gratuito, em substituição a um modelo assistencial individualista, fragmentado e com grande influência da assistência curativista. A constituição do SUS foi o maior movimento de inclusão social vivenciado na história do Brasil (Molina, 2018).

Já na segunda metade da década de 90, com a intensificação das contra reformas de estado por conta do avanço do projeto neoliberal, consolidado pelas privatizações do setor estatal houve uma redução drástica nos investimentos em políticas públicas. Em 17 de junho de 2009, foi aprovada pelo Conselho Nacional de Saúde (CNS), a primeira versão da Carta dos Direitos dos Usuários da Saúde. Este documento é uma importante ferramenta para consolidar os direitos e deveres do exercício da cidadania na saúde em todo Brasil e, assim, garantir o acesso universal e igualitário às ações e serviços de promoção, proteção e recuperação da saúde. A carta é composta por sete diretrizes, constituindo-se: direito à saúde, a tratamento adequado, à atendimento humanizado, a direitos fundamentais, à corresponsabilidade, ao direito à informação e à participação (Brasil, 2018).

Diante desta realidade e das considerações apontadas pela legislação e pelos documentos acima relatados, este estudo tem como objetivo descrever como ocorre o acesso ao direito à saúde na Atenção Primária à Saúde (APS) do Sistema Único de Saúde (SUS) em uma unidade básica de saúde da região metropolitana de Porto Alegre, RS, tendo como referência empírica a vivência junto aos usuários do sistema de saúde. O propósito que norteia este estudo é refletir e analisar as vivências e narrativas dos usuários no cenário de prática de uma profissional residente em um programa de Residência Multiprofissional em Atenção Básica. Isto ocorreu por meio da escuta sensível nas abordagens individuais e coletivas, identificando os caminhos percorridos da Rede de Atenção à Saúde (RAS) para efetivação do seu acesso à saúde, à luz da Carta dos Direitos e Deveres da Pessoa Usuária da Saúde (2018).

Que o direito à saúde está garantido por lei, não existem mais dúvidas, pois observamos esta garantia em muitos textos da nossa legislação, como na Portaria n $\mathrm{n}^{\circ}$ 1.820, de 13 de agosto de 2009, que dispõe sobre os direitos e deveres dos usuários da saúde. Este documento afirma no Art. $2^{\circ}$ que toda pessoa tem direito ao acesso a bens e serviços ordenados e organizados para garantia da promoção, prevenção, proteção, tratamento e recuperação da saúde. Também considera que o acesso será preferencialmente nos serviços de Atenção Básica (AB), integrados por centros de saúde, postos de saúde, unidades de saúde da família e unidades básicas de saúde ou similares mais próximos de sua casa.

Com todos esses documentos legislativos, que afirmam este direito, se levantam questões: A lei basta? Como garantir esse direito no contexto em que estão inseridos os sujeitos? As pessoas têm conhecimento do seu direito? Elas têm acesso a essas informações? E quando o estado não garante esse direito? Estas questões fazem parte das reflexões que este trabalho pretende trazer, já que direito é uma construção e não é efetivado por decreto.

\section{Metodologia}

Trata-se de um artigo sistematizado por meio de um relato de experiências desenvolvidas em contextos de prática da Atenção Primária à Saúde (APS). Visa descrever como ocorre o acesso ao direito à saúde dos usuários da APS do Sistema Único de Saúde (SUS), em uma unidade básica de saúde da região metropolitana de Porto Alegre/RS, tendo como referência empírica a vivência junto aos usuários do sistema de saúde. Nossa perspectiva é de contribuir com análises sobre o vivido, não com a pretensão de definir como é o acesso e os direitos dos usuários, mas sim, dar vistas a micro escala da experiência como estímulo à construção real de possibilidades de ampliação do acesso ao SUS. 
Este estudo teve como cenário de prática, uma Unidade Básica de Saúde (UBS) de um município da região metropolitana de Porto Alegre/RS. Os instrumentos e procedimentos desta análise foram: observação participante, escuta qualificada e diário de campo para sistematização e registro do vivido.

A observação participante consiste na participação real do pesquisador, assumindo, até certo ponto, o papel de membro do grupo (Gil, 2008). Segundo Peruzzo (2017), a observação participante, é uma ferramenta para compreender os fenômenos, afirma que sempre existiu o desejo do conhecimento para além daquele oriundo dos cálculos estatísticos. Destaca como características da observação participante: a) pesquisador (a) se insere e participa das atividades do grupo pesquisado, na condição de observador (a), assim, acompanha o contexto de vida do ambiente estudado; b) pesquisador (a) será autônomo no processo de pesquisa, sendo assim, o grupo investigado não interfere no planejamento da pesquisa, nas informações registradas e nem nas interpretações que serão dadas ao que for observado.

Para a escuta qualificada, é preciso que o pesquisador consiga perceber o universo afetivo, imaginário e cognitivo da outra pessoa. Desta forma, é possível compreender as suas atitudes, comportamentos, sistemas de ideias e valores, símbolos e mitos (Barbier, 2002).

Para o registro das observações deste estudo, utilizamos o diário de campo, sendo este um instrumento de anotações de todas as observações de fatos concretos, fenômenos sociais, acontecimentos, relações verificadas, experiências pessoais do investigador, reflexões e comentários (Falkembach, 1987).

Dentre todos os acompanhamentos e vivências dos usuários que acompanhamos, escolhemos um caso para apresentar neste artigo, por ser representativo e por facilitar a relação deste com a Carta dos Direitos e Deveres da Pessoa Usuária da Saúde. Demos a esta pessoa o nome fictício de Ametista, de forma a que se possa garantir o sigilo da identidade da usuária.

A análise dos dados ocorreu por meio do registro documentado no diário de campo, buscando elementos similares e divergentes nas falas, bem como o seu contexto histórico e social. Utilizou como base também o estudo minucioso do referencial teórico utilizado.

O projeto do presente estudo foi aprovado pelo Comitê de Ética em Pesquisa da Universidade do Vale do Rio dos Sinos (UNISINOS), parecer n $\mathrm{n}^{\circ}$ 3.670.309, obedecendo aos preceitos éticos da Resolução no 510/2016 do Conselho Nacional de Saúde do Ministério da Saúde do Brasil. Este dispõe sobre as normas aplicáveis a pesquisas científicas envolvendo seres humanos, e incorpora, sob a ótica do indivíduo e das coletividades, referenciais da bioética, tais como, autonomia, não maleficência, beneficência, justiça e equidade, dentre outros, e visa a assegurar os direitos e deveres que dizem respeito aos participantes da pesquisa, à comunidade científica e ao Estado.

\section{Resultados e Discussão}

Para a elaboração deste artigo, foi realizada a sistematização dos relatos das observações documentadas no diário de campo no processo de residência ao longo dos anos de 2018/2 e 2019, por meio das categorias direito à saúde e acesso aos serviços de saúde, buscando elementos similares e divergentes nos registros, bem como o seu contexto histórico e social.

Dentre os registros, escolhemos uma vivência por ser esta representativa e emblemática, pois retrata a dificuldade de acesso dos usuários ao serviço de saúde e a garantia do seu direito humano à saúde. Definimos esta situação descrita dentre tantas escutas e vivências do cotidiano no SUS para fins da análise pretendida neste artigo, mas sem dúvida teríamos diversas situações para narrar. O cotidiano é múltiplo, quando narramos o cotidiano, estamos dialogando sob a perspectiva da concepção social do dia a dia, isto é, cotidiano retrata essencialmente as ações das nossas rotinas, é o viver do dia a dia (Guimarães, 2002).

Será apresentada a narrativa que contextualiza o cotidiano do caso, realizando a discussão dos resultados à luz da Carta dos Direitos e Deveres da Pessoa Usuária da Saúde (2018) e da revisão teórica realizada para este estudo. A teoria torna- 
se fundamental para que possa iluminar a prática, conhecer e compartilhar saberes e compromissos. Ela permite que se perceba a realidade inserida num contexto teórico, no caso do SUS, da democracia e da saúde como direito (Santos, 2017).

Importante considerar que estamos nos referindo ao contexto de uma história de vida. O lugar é um município localizado no Rio Grande do Sul, possui uma área territorial $102,738 \mathrm{Km}^{2}$, situa-se na região metropolitana, a $30 \mathrm{~km}$ ao norte de Porto Alegre, capital do estado. Segundo estimativa do Instituto Brasileiro de Geografia e Estatística (IBGE), em 2019, 236.835 pessoas viviam nesse município (Instituto Brasileiro de Geografia e Estatística, 2019).

A rede de APS deste município é composta por 21 Unidades Básica de Saúde (UBS), uma Unidade Básica de Saúde Volante, 13 Estratégias de Saúde da Família (ESF). Também agrega a sua rede de atenção à saúde um Núcleo Apoio a Saúde da Família (NASF), três Centros de Atenção Psicossocial (CAPS), uma Unidade de Pronto Atendimento (UPA) e o setor de Urgência e Emergência do Hospital Municipal, entre outros serviços, caracterizando-se como portas de entrada do SUS para a população desse município (São Leopoldo, 2019).

$\mathrm{O}$ contexto do relato ocorreu em uma tarde de verão, com o sol quente de fevereiro. Ametista, nome dado para não identificá-la, 50 anos, mulher, moradora do município de São Leopoldo, desloca-se até UBS D. Na recepção da unidade solicita conversar com a enfermeira.

Ao entrar na UBS D, a usuária não encontra as informações necessárias sobre os profissionais que estão atendendo tanto na equipe da Atenção Básica (eAB) quanto na equipe da Saúde da Família (eSF). Não existe informativo do número de fichas para os atendimentos do médico clínico, pediatra e ginecologista, nem os dias de atendimento desses profissionais que fazem parte da $\mathrm{ABB}$. No dia anterior, ou até no mesmo dia, é fixado um cartaz em tamanho de uma folha A4 informando o profissional que estará atendendo ou a ausência de um profissional da equipe e o número de fichas disponíveis. Estas informações se restringem aos atendimentos de médicos e dentistas. As ações de outros núcleos como o da enfermagem, e as atividades coletivas realizadas não são divulgadas pela equipe do serviço. Com exceção da sala de vacinas, que tem o seu horário de funcionamento e dias específicos de determinada vacina divulgada, as outras atividades não são divulgadas à população, nem sequer os serviços disponíveis diariamente na UBS D.

Deste modo, é possível referir que a UBS D infringe a sexta diretriz da Carta dos Direitos e Deveres da Pessoa Usuária da Saúde (2018), que descreve que toda pessoa tem direito à informação sobre os serviços de saúde e aos diversos mecanismos de participação. Esta UBS não divulga informações e esclarecimentos sobre a oferta de serviço no local.

Conforme tem sido preconizada pelo Ministério da Saúde/SUS, a oferta de ações e serviços da AB deverá estar disponível aos usuários de forma clara, e de fácil visualização. Deve estar afixado em local visível, próximo à entrada da UBS, a identificação e horário de atendimento; o mapa de abrangência com a cobertura de cada equipe; a identificação do gerente da Atenção Básica no território e dos componentes de cada equipe da UBS; a relação de serviços disponíveis e o detalhamento das escalas de atendimento de cada equipe. Além disso, a oferta deverá ser pública e desenvolvida em parceria com o controle social (Brasil, 2017).

No encontro com Ametista ainda na recepção da unidade, percebe-se ela de rosto vermelho do calor do sol, e junto ao rubor trazia uma expressão de aflição. A enfermeira encontrava-se em um atendimento programado da agenda. Como profissional da saúde, conversamos com ela, que refere que ainda irá demorar naquele atendimento.

Apresento-me para Ametista e questiono se gostaria de começar o seu acolhimento conosco, já que a enfermeira que ela buscava estava ocupada no momento. Ela assente com a cabeça, dizendo que precisa tirar umas dúvidas. Após convidamos para ir a uma das salas de consultório da unidade para uma abordagem individual, enquanto a enfermeira da unidade finaliza o outro atendimento. Durante a nossa conversa, relata que há três dias sentiu um "caroço" nas suas costas e que nesse dia começou a sentir em outras partes do seu corpo: indica seus seios, barriga e peito. Perguntamos se poderíamos fazer o exame físico destas manifestações que vem sentindo em seu corpo, ela balança a cabeça dizendo que sim. Durante a palpação, 
sentimos linfonodos aumentados em região inguinal e axilar e nos locais referidos por Ametista (mamas, abdome, coluna lombar, tórax anterior e posterior).

Nossa conversa segue: conta que realiza acompanhamento em um Hospital em Porto Alegre para investigação de uma síndrome que afeta os ossos. Diz que os médicos de lá já excluíram as hipóteses de artrite ou reumatismo.

Depois disso, desabafa que vêm vivendo dias muitos difíceis, pois solicitou a internação compulsória do filho dependente químico. Refere que ela já havia tentado outras formas de tratamento para ele, mas que não via mais outra saída. Neste momento, sua voz fica embargada quando diz que a qualquer momento o oficial de justiça pode chegar a sua casa para levar o seu filho. Sentimos todo o sofrimento dela nesta decisão, pois como Barbier (2002) conceitua, o pesquisador deve saber sentir o universo afetivo imaginário e cognitivo do outro. A isto chama de escuta qualificada, pois com isso pode compreender suas atitudes, comportamentos, e sistema de ideias, de valores. O profissional de saúde deve respeitar o usuário na singularidade de sua identidade individual e de sua história pessoal, levando em consideração o seu contexto cultural, social e do território em que vive (Corrêa; Ferreira; Cruz. \& Pedrosa, 2011).

Após contar o motivo desta dor física e verificarmos toda a aflição do seu olhar, narra que já havia buscado atendimento em outra UBS. Também havia ido à outra UBS para conversar com a enfermeira, porém não foi acolhida. Esta profissional disse que ali ela não poderia ser atendida, que deveria buscar outro serviço. Ambas as unidades que Ametista procurou são unidades mistas (UBS e ESF) e devem prestar atendimento para toda população do seu entorno que buscar por atendimento, já que o SUS é universal e não pode negar atendimento a ninguém. Pode atender e referenciar a usuária para sua Unidade de Referência, mas não deixar de atendê-la.

De acordo com a PNAB (Brasil, 2017), todas as UBS deverão assegurar o acolhimento e escuta qualificada dos usuários. Isto deve ser feito até mesmo para os usuários que não são da área de abrangência da unidade, realizando o encaminhamento responsável, conforme a demanda apresentada, articulando-se com outros serviços da rede de maneira resolutiva.

Também cabe a todas as unidades mistas, além da disponibilização do mapa com a área demarcada da ESF, outro mapa da área ou lista com os nomes das ruas que devem ser atendidas pela UBS, para que a informação apresente-se de forma transparente e objetiva para a pessoa usuária do SUS. Isto evita os itinerários terapêuticos migratórios, como no caso de Ametista, que conseguiu ser atendida somente depois de buscar a segunda unidade de saúde.

Os caminhos que os usuários enfrentam para alcançar a garantia aos serviços de saúde são muitos e o número de atendimentos diários, por serviço anteriormente definido como fichas, resulta em um desequilíbrio entre oferta de serviços e a demanda de atendimentos. Esta condição leva o usuário a enfrentar filas noturnas para garantir o atendimento pela manhã (Nonnenmacher; Weiller \& Oliveira, 2011). Esta realidade está presente no cotidiano das pessoas usuárias da UBS D e leva muitas a realizar um itinerário terapêutico migratório na busca por atendimento. É importante destacar que o modelo de acesso com filas "madrugadoras" resulta no atendimento principalmente dos mais fortes e, muitas vezes, exclui os que mais precisam de assistência, rompendo com o princípio da equidade (Nonnenmacher et al., 2011). Na prática ainda existe o acesso seletivo aos serviços do SUS, ele é focalizado e excludente (Assis \& Jesus, 2012). A Carta dos Direitos e Deveres da Pessoa Usuária da Saúde (2018) traz como primeira diretriz que toda pessoa tem direito, em tempo hábil, ao acesso a bens e serviços ordenados e organizados para garantia da promoção, prevenção, proteção, tratamento e recuperação da saúde. Na segunda diretriz, refere que toda pessoa tem direito ao atendimento integral, aos procedimentos adequados e em tempo hábil a resolver o seu problema de saúde, de forma ética e humanizada. Na terceira, aponta que toda pessoa tem direito ao atendimento inclusivo, humanizado e acolhedor, realizado por profissionais qualificados, em ambiente limpo, confortável e acessível. Na quarta diretriz afirma que toda pessoa deve ter seus valores, cultura e direitos respeitados na relação com os serviços de saúde. 
Em interconsulta com a enfermeira da unidade, Ametista foi orientada a buscar atendimento no hospital no qual faz investigação sobre sua saúde. Em caso de dor, deve buscar o Centro de Saúde ou a Unidade de Pronto Atendimento do município, pois a UBS D encontrava-se sem médico, devido à saída de profissionais médicos do Programa Mais Médicos.

No final do acolhimento, Ametista agradeceu a escuta, e disse que precisava saber para onde ir. Referiu que estava com medo de ter um câncer galopante. A palavra câncer, por si só, já traz a ideia da dor e da morte, o que causa medo e ansiedade a quem a ouve. Quanto mais cedo uma pessoa como Ametista for atendida, menos tensão e angústia vão causar a ela.

Acolher é uma ação inerente à equipe de saúde, um direito do usuário e um princípio do SUS. Neste direito está implícito o papel de "humanizar" as relações entre usuários e trabalhadores. Isto significa compreender que os sujeitos são dotados de desejos e necessidades e precisam ser respeitados por isso (Brasil, 2013). O acolhimento possibilita a criação de vínculos, contribuindo para a percepção dos usuários a respeito das informações recebidas, seu entendimento e reflexão sobre as suas demandas, estabelecendo a satisfação ou não com a atenção recebida (Corrêa et al., 2011).

É possível verificar que o nosso acolhimento trouxe satisfação para Ametista, pois ela agradece a escuta, e diz que "só precisava saber aonde ir e o que fazer". O acesso aos serviços de saúde é um direito de todo (a) brasileiro (a), estando associado aos princípios do acolhimento e do vínculo. Qualquer pessoa da equipe pode exercer este papel de acolher, ouvir a queixa e encaminhar (Corrêa et al., 2011).

Ainda que Ametista tenha acessado e sido acolhida na UBS D, como prevê a primeira, terceira e quarta diretriz da Carta dos Direitos e Deveres da Pessoa Usuária da Saúde (Brasil, 2018), não foi possível ofertar um atendimento integral. Esta impossibilidade ocorreu em função da falta de médico no serviço de saúde. Ela, entretanto, foi acolhida pela fisioterapeuta, assistente social e enfermeira, e depois encaminhada para outro serviço. A segunda diretriz da Carta dos Direitos e Deveres da Pessoa Usuária da Saúde refere que é isso o que é preciso fazer, pois toda pessoa tem direito ao atendimento integral, aos procedimentos adequados e em tempo hábil a resolver o seu problema de saúde. Devido à falta de médicos, o serviço procurado não conseguiu ser resolutivo, pois não resolveu o problema de Ametista, somente a encaminhou a outro nível de atenção à saúde. Fez o acolhimento e a escuta qualificada da demanda da usuária para fazer este encaminhamento. Entretanto, quando se refere à humanização do atendimento resolutivo, é essencial ter disponível o número adequado de profissionais de saúde para oferecer a atenção em saúde (Nonnenmacher et al., 2011), caso contrário o usuário fica "rolando" de um serviço para o outro sem conseguir resolver seu problema de saúde.

A clínica ampliada vem sendo considerada como estratégia de qualificação da porta de entrada da saúde, visto que a ampliação do núcleo e do campo de atuação dos profissionais produzirá maior resolutividade para as demandas que chegam ao nível primário de atenção à saúde, assim, reduzindo os encaminhamentos para outros níveis de atenção à saúde (Nonnenmacher et al., 2011). Entretanto, com a saída dos médicos cubanos, o "Programa Mais Médicos", foi afetado pela falta desses profissionais e muitos serviços básicos de saúde ficaram sem médicos.

No estudo de Corrêa et al. (2011), além de descrever a APS como porta de entrada preferencial para o sistema de saúde, os autores referem que, quando organizada, a APS é capaz de atender e resolver a maioria das necessidades de saúde da população, reduzindo os encaminhamentos para a atenção especializada, ou seja, aos níveis de atenção com mais complexidade tecnológica. No entanto, quando não se garante a APS como porta de entrada de acesso preferencial, que esteja disponível e seja resolutiva para o atendimento às necessidades de saúde da população, além da violação do direito do usuário, compromete-se a assistência adequada, ocasionando a busca do serviço de saúde em outro nível de atenção.

Nonnenmacher et al. (2011) identificam em seu estudo que quando o usuário encontra barreiras e limites no acesso à saúde, muitas vezes, a única alternativa é buscar atendimento nas Unidades de Pronto Atendimento. Em outras vezes, o próprio serviço faz este encaminhamento, como foi o caso de Ametista. Isto é muito ruim para a organização do SUS, pois faz com que 
os usuários percebam que nem sempre há atendimento nas UBS e vão direto para o serviço especializado. Isto é contrário a um dos princípios básicos do SUS que é a referência e contra-referência.

Esta dificuldade de acesso ao nível primário de atenção à saúde reflete em uma demanda excedente na busca de atendimento em unidades de Pronto Atendimento, realidade do cotidiano das pessoas usuárias do SUS da UBS D. A população se dirige mais as unidades de Pronto Atendimento em busca de solução para as suas necessidades, provavelmente como reflexo de uma baixa acessibilidade às UBS. Os fatores que mais motivam esta escolha são o acesso e a resolutividade da atenção, os quais têm levado o usuário a buscar acesso à saúde onde haja porta aberta (Nonnenmacher et al., 2011).

Além deste problema de organização do SUS, ainda há a falta de articulação entre as diferentes portas de entrada do sistema, o que leva o usuário a peregrinar pelos serviços em busca de resolução para as suas necessidades e de atenção para as suas demandas. Ametista foi um desses casos, pois precisou migrar de uma unidade para outra para conseguir assegurar o seu direito de atenção à sua demanda, o que caracteriza a baixa resolutividade dos serviços e da rede de atenção à saúde. Neste sentido, é necessário que o sistema, sendo responsável pelo cuidado do usuário, seja promotor de condições adequadas a cada caso, garantindo, desta forma, a continuidade do cuidado desde o primeiro atendimento até a resolução da demanda (Nonnenmacher et al., 2011).

Avaliar o acesso das pessoas ao SUS consiste em um indicador sensível para analisar os serviços ofertados pelo sistema público de saúde (Nonnenmacher et al., 2011). As barreiras de acesso à saúde encontradas neste estudo retratam uma realidade local, mas é possível que represente mais de um serviço uma vez que o Programa Mais Médicos eliminou os médicos cubanos, isto acabou por afetar o atendimento na atenção básica em saúde.

Ametista mora em um território de vazio assistencial, mesmo sua casa estando próxima de duas UBS, ela não recebe a cobertura da ESF. Esta é a realidade de uma grande totalidade da população moradora neste município, pois ainda tem uma baixa cobertura da ESF, assim como da $\mathrm{AB}$ enquanto política que visa melhorar o acesso das pessoas aos serviços de saúde.

Segundo o relatório da cobertura populacional estimada de equipes de Saúde da Família (eSF) e de equipes de Atenção Básica (eAB), que monitora o acesso aos serviços de Atenção Básica disponível no sistema e-Gestor Atenção Básica, houve um decréscimo na cobertura de eSF e eAB no período de outubro de 2018 a setembro de 2019, no município de São Leopoldo. Em outubro de 2018, a cobertura de eSF era de 19,42\% passando em setembro de 2019 para 13,22\%. Da mesma forma, em relação à cobertura das eAB que reduziu de 36,57\% em outubro de 2018 para 33,84\% em setembro de 2019 (Brasil, 2019).

Este panorama retratado da cobertura da rede de AB para o território do município de São Leopoldo apresenta-se em contraposição ao que vem sendo anunciado há 40 anos na Declaração de Alma-Ata. Esta qualifica a APS como a estratégia para garantia do direito universal à saúde e ao acesso a rede de serviços e atenção à saúde. Além disso, preconiza que desfrutar do melhor estado de saúde é um direito fundamental de todo ser humano (Mendonça, 2018; Molina, 2018).

O conceito de atenção primária integral foi propagado mundialmente, estando a APS integrada aos cuidados em saúde e ao desenvolvimento econômico e social. É considera como o meio para reduzir as iniquidades em saúde, promover a participação social e contribuir para a garantia do direito à saúde (Kemper et al., 2018). A PNAB (Brasil, 2017) considera as equipes de Saúde da Família como a estratégia prioritária para de expansão, qualificação e consolidação da atenção à saúde em nível primário com o objetivo de reorganizar a $\mathrm{AB}$, de acordo com os preceitos do SUS.

A sétima diretriz da Carta dos Direitos e Deveres da Pessoa Usuária da Saúde refere que toda pessoa tem direito a participar dos Conselhos e Conferências de Saúde. Entretanto, este direito não é garantido, visto que não existe a formação do Conselho Local de Saúde no território em que está localizada a UBS D, negligenciando o controle social e o incentivo à participação social. $\mathrm{O}$ fortalecimento do controle social é o que sustenta as lutas pelo direito humano à saúde, pois ele promove a atuação da população à frente da garantia dos direitos sociais (Centro de Educação e Assessoramento Popular, 2017). 
Um dos principais problemas a serem enfrentados para que haja efetividade no funcionamento do SUS são as desigualdades de acesso. Assim, deve serem reafirmados os princípios do SUS: a universalidade, a equidade e a integralidade e as diretrizes do SUS: a descentralização, o atendimento integral e a participação da comunidade. Para isto, é necessário construir uma consciência cidadã e derrotar o conformismo social, mediante a emancipação de sujeitos capazes de intervir nesta realidade, garantindo o acesso universal e equitativo como construção social (Assis \& Jesus, 2012).

Desta maneira, é possível observar que Ametista e outros vários usuários enfrentam barreiras e limites impostos no acesso ao SUS e a rede de atenção primária à saúde, o que infringe as diretrizes e princípios do SUS. Para que essas iniquidades não ocorram, é importante ressaltar a importância do acolhimento e da humanização do atendimento, conceitos presentes na Política Nacional de Humanização. Esta tem como uma das suas prioridades a busca pela redução das filas e do tempo de espera que ocorre por meio da ampliação do acesso e de um atendimento acolhedor e resolutivo (Nonnenmacher et al., 2011).

A Política Nacional de Humanização também reforça a necessidade da escuta qualificada que permite aos trabalhadores desvelarem as principais_necessidades em saúde postas pelos usuários. Sendo assim, é um forte dispositivo que possibilita e assegura o acesso adequado desses usuários às tecnologias apropriadas às suas necessidades, ampliando a equidade nas ações de saúde (Brasil, 2013).

\section{Considerações Finais}

A trajetória de um pouco mais 30 anos do Sistema Único de Saúde, no Brasil, produziu importantes mudanças na atenção à saúde da população. Entretanto, é inevitável pensar que hoje vivemos o cosmocapitalismo em um sistema de normas e acúmulo de capital, combustível da atual guerra econômica que semeia as desigualdades e vulnerabilidade social e apressa o enfraquecimento da democracia (Laval \& Dardot, 2017).

Uma pergunta ecoa aos ouvidos: Como garantir o acesso à saúde em um país como o Brasil, no qual o direito a um sistema público e universal de saúde está previsto na Constituição Federal? Com isso, surge uma nova discussão a respeito da cobertura universal em saúde.

Autores como Kemper et al. (2018) trazem a necessidade de um novo marco, ou de uma nova meta para o SUS, levando em consideração que o sistema está sustentado pelo alicerce legal do direito à saúde e dos princípios do SUS, entre os quais declara a universalidade de acesso. É importante sublinhar que até o presente momento, o SUS não atingiu os princípios da universalidade e da integralidade. Diante deste cenário, a cobertura universal deixaria de ser apenas um princípio e se tornaria uma meta (Kemper et al., 2018). Esta é a realidade do domínio da sociedade por grupos econômicos e classes sociais que usam dos seus poderes e privilégios para manter a guerra econômica. É o que presenciamos diariamente, a tragédia do não comum, do não universal (Laval \& Dardot, 2017).

A formulação dos direitos está historicamente nas mãos da classe detentora do poder econômico, em benefício dos seus interesses. Contudo, os direitos sociais foram concebidos em um terreno de lutas e tensões, movido pela classe trabalhadora em busca da democracia (Garcia et al., 2020)

O SUS se constitui em um campo de práticas sociais, situado sob uma superfície de tensões que o posiciona como lugar permanente de disputas, sociais e históricas (Merhy, 2012).

Leite e Mafra (2010) mencionam que os serviços de saúde no Brasil, necessitam ir além de prevenir, curar e reabilitar. Eles precisam contribuir para gerar uma visão reflexiva e de ações de diferentes sujeitos sobre o social, conscientes de seus direitos e do "direito de ter direitos". Assim, devemos reconhecer o outro como sujeito produtor de direito e não apenas como um ser cumpridor do direito (Merhy, 2012). 
O direito concretizado em leis, não tem efetivado a garantia dos direitos da sociedade, ao invés, de ser uma ferramenta de promoção da justiça e da igualdade, tem ao contrário, reafirmado um direito conservador, demarcando os limites de uma sociedade fragmentada por classes (Garcia et al., 2020).

Como dizem Laval e Dardot, (2017, p. 20-21) nada seria pior do que deixar o direito nas mãos daqueles cuja profissão é decretá-lo. [...] o sistema de normas está sempre em jogo nos conflitos, e o direito como tal é um terreno de luta. Vivemos na sociedade das catracas, que provoca a domesticação dos sujeitos. Neste mundo organizado e delimitado por barreiras, por cercas e muros, o Estado se torna o obstaculizador das trocas e construções de saberes (Han, 2015).

Blas (2014) reforça a importância de desintoxicarmo-nos da lógica do mercado capitalista, que gera como consequência mais visível da crise a violação dos direitos humanos e a deterioração da qualidade de vida das pessoas. Necessitamos poder ficar afastados da cidadania mercantilizada, "consumo, então eu existo" e nos reaproximarmos do ideal democrático de cidadania. Devemos colocar a sustentabilidade da vida no centro de todo o nosso processo de viver, o que exige um novo pacto social baseado no direito universal de cuidar: "Cidadania”, CUIDADANIA!

Este artigo pretende deixar algumas reflexões e marcar a triste realidade em que vivem hoje (2021) os usuários do Sistema Único de Saúde, sistema cada vez mais sucateado em prol dos interesses dos sistemas privados de saúde. Há muito ainda no que refletir e pesquisar quando se trata de entender como têm sido garantidos os direitos dos usuários do SUS. Da mesma forma, entendemos que há muito pelo que lutar para que estes direitos constitucionais possam ser garantidos e ampliados de forma a que a população possa ter seu direito à vida e à saúde reafirmados.

Os elementos sobre o tema proposto são diversos, e não se esgotam com este estudo, esta experiência pode ser um estímulo para a construção de novos estudos que abordem possibilidades de ampliação da cidadania e a redução das iniquidades do acesso à saúde.

\section{Referências}

Assis, M. M. A. \& Jesus, W. L. A. (2012) Acesso aos serviços de saúde: abordagens, conceitos, políticas e modelo de análise. Ciência \& Saúde Coletiva. $17(11), 2865-75$.

Barbier, R. (2002) Escuta sensível na formação de profissionais de saúde. Anais da Conferência na Escola Superior de Ciências da Saúde. http://www.barbierrd.nom.fr/ESCUTASENSIVEL.PDF.

Blas, A. (2019). La (Sosteniblidad de La) Vida enPeligro In BLAS, A. La Revolución de Los Cuidados.InteRed, dic. http://redciudadaniaglobal.org/wpcontent/uploads/2015/10/La-Revolucion-de-los-cuidados.pdf.“.

Brasil. (1988). Constituição 1988. Constituição da República Federativa do Brasil de $1988 . \quad$ Presidência da República. http://www.planalto.gov.br/ccivil_03/Constituicao/Constituicao.htm.

Brasil. (2009). Ministério da Saúde. Portaria $n^{\circ} 1.820$, de 13 de agosto de 2009. Dispõe sobre os direitos e deveres dos usuários da saúde. Brasília, DF: Ministério da Saúde. http://bvsms.saude.gov.br/bvs/saudelegis/ gm/2009/prt1820_13_08_2009.html.

Brasil. (2013). Ministério da Saúde. Política Nacional de Humanização. Ministério da Saúde.

Brasil. (2017). Ministério da Saúde. Portaria $n^{\circ}$ 2.436, de 21 de setembro de 2017. Aprova a Política Nacional de Atenção Básica, estabelecendo a revisão de diretrizes para a organização da Atenção Básica, no âmbito do Sistema Único de Saúde (SUS). Ministério da Saúde. http://bvsms.saude.gov.br/bvs/saudelegis/gm/2017/prt2436_22_09_2017.html.

Brasil. (2018). Ministério da Saúde. Conselho Nacional de Saúde. Carta dos Direitos e deveres da Pessoa Usuária da Saúde. Ministério da Saúde.

Brasil. (2019). Ministério da saúde. Cobertura da Atenção Básica Unidades São Leopoldo. In: e-Gestor AB. https://egestorab.saude.gov.br/p aginas/acessoPublico/relatorios/relHistoricoCoberturaAB.xhtml.

Centro de Educação e Assessoramento Popular. (2017). O SUS e a efetivação do direito humano à saúde. Saluz.

Conselho Nacional de Saúde. (2019). Eixo Temático I Saúde como Direito. In: Documento Orientador de Apoio aos Debates da $16^{a}$ Conferência Nacional de Saúde. Conselho Nacional de Saúde.

Corrêa, A. C. P.; Ferreira, F.; Cruz, G. S. P. \& Pedrosa, F. (2011). Acesso a serviços de saúde: olhar de usuários de uma unidade de saúde da família. Revista Gaúcha Enfermagem, Porto Alegre, 32(3), 451-7.

Falkembach, E. M F. (1987). Diário de Campo: um instrumento de reflexão. In Contexto e educação. Ijuí: Inijuí.2(7), 19-24. 
Research, Society and Development, v. 10, n. 12, e489101220704, 2021

(CC BY 4.0) | ISSN 2525-3409 | DOI: http://dx.doi.org/10.33448/rsd-v10i12.20704

Garcia, F. de B. S., Ruviaro, D., Semzezem, P., \& Toretta, E. T. (2020). A contradição entre o Estado e a garantia de direitos no atual contexto de crise do capitalismo. Research, Society and Development, 9 (10). http://dx.doi.org/10.33448/rsd-v9i10.8325

Gil, A. C. (2008). Métodos e técnicas de pesquisa social. (6a ed.), Atlas.

Guimarães, G. T. D. (2002). O não-cotidiano do cotidiano In Guimarães, G. T. D. Aspectos da teoria do cotidiano: Agnes Heller em perspectiva. Porto Alegre: EDIPUCRS.

Han, B. (2015). Sociedade do Cansaço. (2a ed.), Vozes.

Instituto Brasileiro de Geografia e Estatística. (2019). Cidades. Rio Grande do Sul. São Leopoldo. Informações Completas. https://www.ibge.gov.br/estatisticas-novoportal/por-cidade-estado-estatisticas.html?t=destaques\&c=4318705.

Kemper, E. S; Tasca, R.; Harzheim, E.; Jiménez, J. M. S.; Hadad, J. \& Sousa, F. (2018). Cobertura universal em saúde e o Programa Mais Médicos no Brasil. Rev. Panam. Salud Publica, 42. https://doi.org/10.26633/RPSP.2018.1

Laval, C.\& Dardot, P. (2017). Comum - Ensaios Sobre a Revolução no Século XXI. Boitempo.

Leite S. N. \& Mafra A. C. (2010). Que direito? Trajetórias e percepções dos usuários no processo de acesso a medicamentos por mandados judiciais em Santa Catarina. Ciência \& Saúde Coletiva. 15(1), 1665-72.

Mendonça, E._(2018). Alma-Ata 1978-2018: a trajetória da saúde pública, pertos e distantes do bem-estar social. Rev. Saúde em Foc. 3(1), 19-23.

Merhy, E. (2012). Saúde e Direitos: tensões de um SUS em disputa, molecularidades. Saúde Soc.21(2), 267-79.

Molina, J. (2018). Saúde universal com equidade, sem deixar ninguém para trás. Rev. Panam Salud Publica. 42. https://doi.org/10.26633/RPSP.2018.173

Nonnenmacher, C. L.; Weiller, T. H.\& Oliveira, S. G. (2011). Acesso à saúde: limites vivenciados por usuários do SUS na obtenção de um direito. Cienc Cuid Saude, 10(2), 248-55.

Paim, J. S.A. (2013). Constituição Cidadã e os 25 anos do Sistema Único de Saúde (SUS). Cad. Saúde Pública. 29(10), 1927-53.

Peruzzo, C. M. K. (2017). Pressupostos epistemológicos e metodológicos da pesquisa participativa: da observação participante à pesquisa-ação. Estudios sobre las Culturas Contemporáneas. 23(3) 161-90.

Santos, R. F. Prefácio. (2017). O SUS e a efetivação do direito humano à saúde. In Centro de Educação e Assessoramento Popular. Saluz.

São Leopoldo. (2019). Prefeitura Municipal. Saúde. Escolha sua unidade. https://www.google.com/maps/d/viewer?mid=1jVYG81Ei_X3vd aXfm37Gaefm9_DOdN e\&11=-29.751579904616747\%2C-51.13919014999999\&z=13. 